\title{
COMPONENTES BIOGÊNICOS COMO INDICADORES AMBIENTAIS DA PLATAFORMA CONTINENTAL DO ESTADO DE SERGIPE E SUL DE ALAGOAS
}

\author{
BIOGENIC COMPONENTS AS ENVIRONMENTAL INDICATORS OF THE CONTINENTAL \\ PLATFORM OF THE STATE SERGIPE AND SOUTH OF ALAGOAS
}

\section{Jonas Ricardo dos SANTOS ${ }^{1}$; Rosemeri Melo e SOUZA²; Edilma ANDRADE ${ }^{3}$; Luiz Carlos da Silveira FONTES ${ }^{4}$}

${ }^{1,2}$ Programa de Pós-Graduação em Desenvolvimento e Meio Ambiente - PRODEMA; jonasricardo@gmail.com Universidade Federal de Sergipe, Av. Marechal Rondon, s/n, Jd. Rosa Elze, São Cristóvão - SE.

2 Departamento de Engenharia Ambiental - DEAM/UFS; rome@ufs.br

${ }^{3}$ Departamento de Geologia - DGEOL/UFS; edilmaa@gmail.com

${ }^{4}$ Laboratório GEORIOEMAR/ Departamento de Engenharia de Pesca e Aquicultura - DEPAQ/UFS; luizfontes@gmail.com

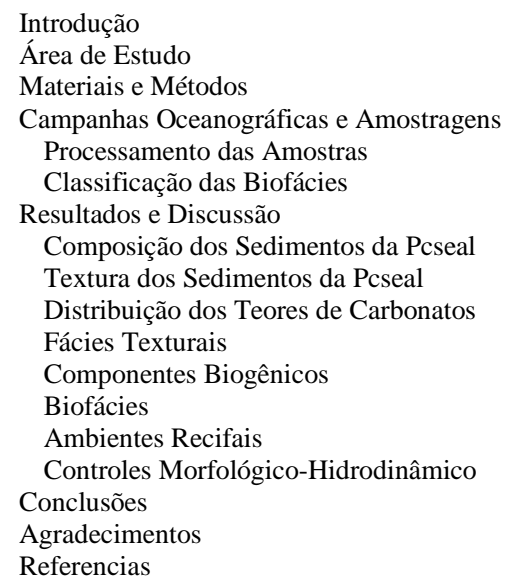

RESUMO - O presente trabalho tem como objetivo caracterizar a distribuição dos componentes biogênicos e correlacionar aos fatores ambientais como a profundidade, morfologia, composição e granulometria dos sedimentos superficiais da Plataforma Continental de Sergipe e sul de Alagoas. Foram realizadas análises de identificação da composição e componentes biogênicos em 423 amostras de sedimentos superficiais. A determinação dos componentes biogênicos dos sedimentos foi realizada em lupa binocular em duas frações granulométricas, obtidas através do processo de peneiramento mecânico (areia fina a média e areia muito grossa a grânulo) e posteriormente separados de forma aleatória, 200 grãos para a análise composicional e de biodetritos. Os resultados indicam que esta plataforma é mista siliciclástica-carbonática e a transição da composição sedimentar com o aumento da profundidade, dos sedimentos de origem continental para os sedimentos biogênicos, sendo esta característica interrompida pelas zonas lamosas do São Francisco e Japaratuba. Os componentes biogênicos mais abundantes são os foraminíferos e a algas vermelhas, responsáveis pela formação de um banco carbonáticos na plataforma externa e a distribuição dos sedimentos biogênicos na plataforma continental SEAL resulta de um ajuste morfodinâmico entre a circulação e a topografia da plataforma.

Palavras-chave: Biodetritos; algas calcárias; Sedimentos Carbonáticos; Plataforma Continental.

\begin{abstract}
This study aims to characterize the distribution of biogenic components and correlate to environmental factors such as depth, morphology, composition and grain size of surface sediments of the Continental Shelf of Sergipe and south of Alagoas. Analyzes of composition identification and biogenic components were performed in 423 superficial sediment samples. A binocular magnifying glass was used to determine the biogenic components of the sediments in two granulometric fractions, obtained through the mechanical sieving process (fine to medium sand and very coarse sand to granule) and then randomly separated, 200 grains for compositional analysis and of biodetrites. The results indicate that this platform is mixed siliciclastic-carbonate and the transition of the sedimentary composition with the increase of the depth of the sediments of continental origin to the biogenic sediments, being this characteristic interrupted by the mud zone of São Francisco and Japaratuba. The most abundant biogenic components are foraminifera and red algae, responsible for the formation of a carbonate bank on the outer platform and the distribution of the biogenic sediments in the SEAL continental shelf results from a morphodynamic adjustment between the circulation and the topography of the platform.
\end{abstract}

Keywords: Biodetrites; Calcareous Algae; Carbonic Sediments; Continental shelf.

\section{INTRODUÇÃO}

A maior parte dos componentes biogênicos continental é produzido localmente e controlado dos sedimentos superficiais da plataforma pelas condições ambientais de cada região. Em 
função disso, a análise da distribuição espacial e a abundância relativa dos biodetritos contidos nestes sedimentos podem fornecer informações importantes para a caracterização ambiental e sobre os condicionantes da sedimentação (Poggio et al., 2009; Rebouças, 2010).

Muitos são os trabalhos desenvolvidos anteriormente na plataforma continental brasileira, mais precisamente na plataforma continental do Nordeste, no qual focam a geomorfologia de fundo, textura da cobertura sedimentar, composição de minerais pesados, entretanto menor atenção tem sido dada a sedimentação biogênica (Poggio et al., 2009, Santos, 2010, Nascimento, 2011; Costa, 2015).

A sedimentação marinha da plataforma continental de Sergipe foi analisada em alguns trabalhos, como Guimarães (2010), Nascimento (2011) e Fontes et al. (2017) que caracterizaram a sedimentação holocênica, com ênfase na distribuição espacial dos principais componentes bioclásticos e siliciclásticos do sedimento, e suas contribuições para a formação do sedimento superficial, comparando as características bióticas e abióticas.

$\mathrm{O}$ uso dos sedimentos biogênicos como indicadores de parâmetros ambientais tem como foco principal a descrição dos processos hidrodinâmicos atuantes sobre uma dada área podendo, assim, ser indicadores de aspectos, tais como: a sua origem espacial (autóctones e/ou alóctones; Bergue \& Coimbra, 2008; Nicolaidis, 2008), o processo de sedimentação (grãos atuais e/ou relíquias; Emery, 1968; Dias, 2004), o tipo de transporte sofrido (saltação, rolamento e/ou suspensão; (Popp, 2002), a intensidade do transporte (nível de arredondamento; (Pilkey et al., 1967), a ocorrência de retrabalhamento no sedimento (grau de empacotamento, selecionamento dos bioclastos e coloração; Leão \& Machado, 1989; Simões \& Holz, 2004), ocorrência de bioerosão (Lorenzo \& Verde, 2004).

Associações de foraminíferos são também amplamente usados como organismos indicadores para monitorar poluição humana na região costeira (Alve, 1991, 1995; Eichler et al., 2012). Assim, a partir da análise conjunta dos componentes biogênicos é possível realizar caracterizações ambientais, reconstruções paleoambientais e estabelecer dados paleoecológicos.

Devido a ampla variedade de sedimentos biogênicos e siliciclásticos associados, é de fundamental importância a identificação dos biogênicos, pois indica os organismos presentes e possibilita o estudo das condições ambientais (Mutti \& Hallock, 2003). Desta forma, os componentes biogênicos podem ser classificados em três categorias: Indicadores ambientais, que refletem diretamente o estado abiótico ou biótico do ambiente; indicadores ecológicos, que refletem o impacto de mudanças ambientais em um habitat, comunidade ou ecossistema; e indicadores de biodiversidade, que são indicativos de uma taxa, ou toda a biodiversidade, em uma área definida (TejedaCruz et al., 2008).

Desse modo, dada a importância dos componentes biogênicos como indicadores de parâmetros ambientais, o presente trabalho tem por objetivo caracterizar a distribuição dos componentes biogênicos e correlacionar aos fatores ambientais como a profundidade, morfologia, composição e granulometria dos sedimentos superficiais da Plataforma Continental de Sergipe e sul de Alagoas - PCSEAL.

\section{ÁREA DE ESTUDO}

A área correspondente ao presente trabalho compreende a Plataforma Continental do Estado de Sergipe e o sul do Estado de Alagoas PCSEAL, no trecho situado entre o Pontal do Coruripe e a foz do rio Piauí-Real e limitada pelas isóbatas de 5 e 60 metros de profundidade (Figura1).

Esta região se caracteriza pelo baixo aporte fluvial, maior influência das Águas Tropicais de Superfície (ATS) da Corrente Sul Equatorial (CSE). O aporte fluvial é limitado e a predominância das águas tropicais de superfície (ATS) da CSE na plataforma se reflete claramente na predominância das feições de carbonatos, dominados por cascalho e areia carbonática biogênica de algas calcárias (Coutinho, 2000; Guimarães, 2010 e Fontes et al., 2017).

Nas proximidades dos cânions do São Francisco e do Japaratuba durante os meses de verão, verificam-se águas com as menores temperaturas e ricas em nutrientes sugerindo que nestes locais esteja ocorrendo o fenômeno da ressurgência da Água Central do Atlântico Sul (ACAS). A ressurgência ocorre durante o verão controlado pelo regime de ventos predominantes de norte-nordeste. Durante os meses mais chuvo- 
sos a salinidade superficial apresenta valores mais baixos provavelmente por influência do rio São Francisco (Paes et al., 2007). Os valores de temperatura apresentaram-se em torno de $26^{\circ} \mathrm{C}$ e de salinidade na faixa de 36 a 38\% (Silveira et al., 1994; Paes et al., 2007; Guimarães, 2010). A zona costeira do rio São Francisco foi drasticamente alterada pela construção de uma série de barragens na bacia do rio entre as décadas de 1970 e 1990. Sua vazão média anual de mais de $3.000 \mathrm{~m}^{3} / \mathrm{s}$ sofreu um declínio de $80 \%$ desde então. Sua pulsação sazonal natural foi regulada para um fluxo quase constante de $\sim 600 \mathrm{~m}^{3} / \mathrm{s}$ (CHESF, 2018) e aproximadamente 95\% dos Sólidos Totais em Suspensão - STS do rio é retido dentro dos reservatórios da barragem
(Medeiros et al., 2007).

Antes da construção das barragens, o rio era turvo com valores médios de concentrações de STS próximas a $70 \mathrm{~g} / \mathrm{m}^{3}$ (Milliman, 1975); as condições fluviais e estuarinas desde então tornaram-se oligotróficas e transparentes com valores médios de concentrações de STS próximas a $5 \mathrm{~g} / \mathrm{m}^{3}$ (Knoppers et al., 2006; Medeiros et al., 2007; 2011).

O impacto das barragens alterou assim consideravelmente os processos estuarinos, o potencial de produtividade do litoral, o transporte de sedimentos e também a erosão costeira foi drasticamente aumentada (Knoppers et al., 2006; Bittencourt et al., 2007; Medeiros et al., 2011; Oliveira et al., 2012).
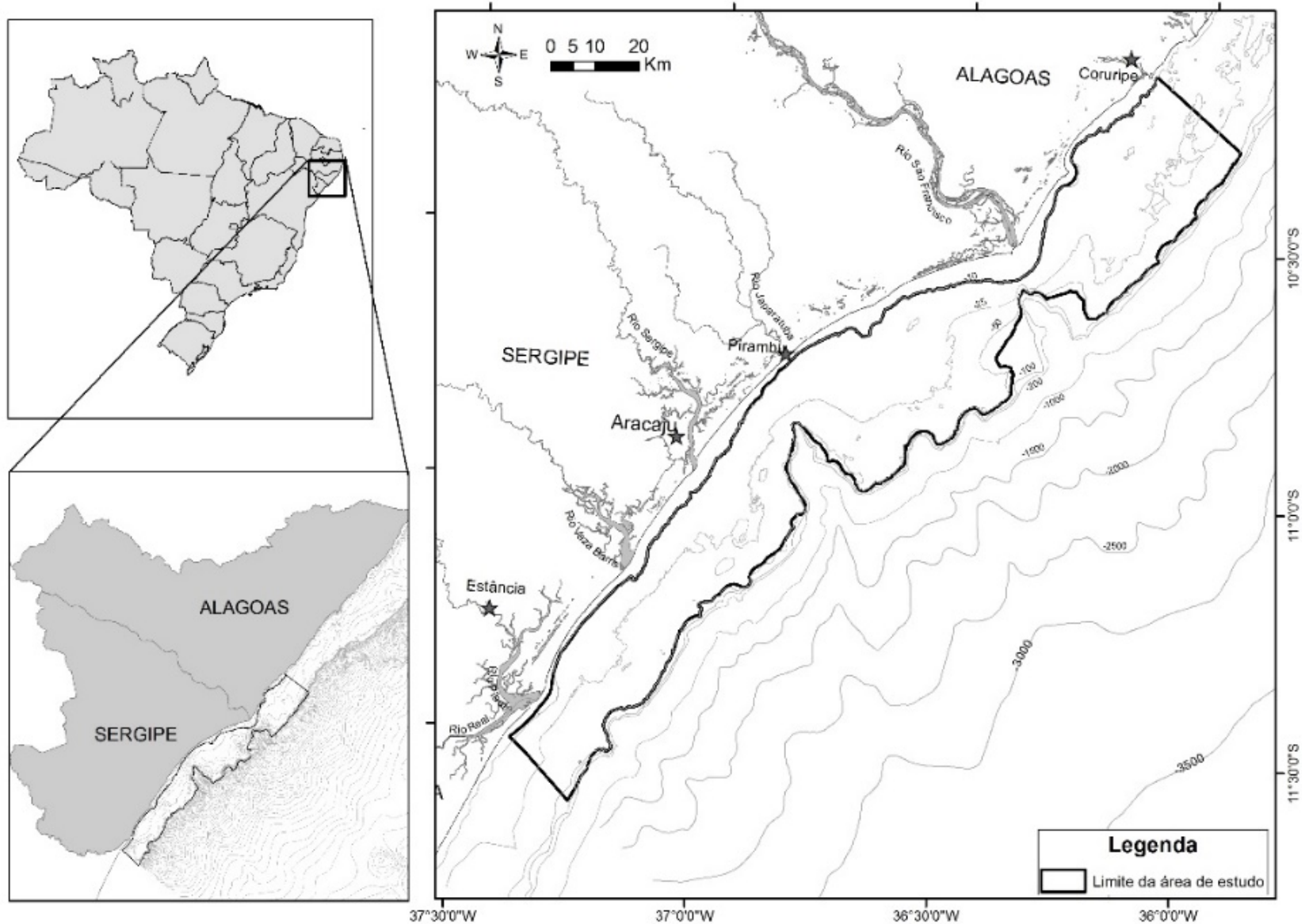

Figura 1 - Área de estudo compreendendo a plataforma continental de Sergipe e Sul de Alagoas.

\section{MATERIAIS E MÉTODOS}

Campanhas Oceanográficas e Amostragens

A coleta de amostras de fundo da plataforma continental corresponde a uma área de aproximadamente $5.000 \mathrm{~km}^{2}$ e comprimento de $210 \mathrm{~km}$, no trecho compreendido entre o Pontal de Coruripe - AL, no extremo norte, e a desembocadura do rio Piauí-Real - SE, situada no extremo sul.

Os transectos de amostragem foram planejados para se estender da costa até a quebra da plataforma e início do talude continental, em torno da isóbata de $50 \mathrm{~m}$, considerada como limite da plataforma continental na região. As estações amostrais foram numeradas em cada transecto de forma crescente no sentido da mais rasa para a mais profunda.

O planejamento de coleta de amostras de 
fundo foi realizado através de perfis perpendiculares à linha de costa, com espaçamento de $2,5 \mathrm{~km}$, os quais foram denominados transectos. Em cada transecto foram lançadas as estações de coleta de amostras de sedimentos de fundo, espaçadas a cada $2 \mathrm{~km}$, formando assim uma malha de amostragem regular de 2,5 x 2,0 km. Os transectos e as estações de amostragem foram lançadas sobre a base cartográfica digital com o uso do programa ArcMap 10.0.

A obtenção de dados primários e a coleta de amostras de sedimentos da PCSEAL foram efetuadas através de 4 (quatro) campanhas oceanográficas (Tabela 1). A campanha
Oceanográfica 1 consistiu no levantamento sedimentológico e perfis batimétricos da plataforma continental norte de Sergipe e sul de Alagoas, mais especificamente a área da plataforma continental compreendida entre o Pontal do Coruripe - Alagoas e a foz do rio Japaratuba Sergipe (Figura 2). A $1^{\text {a }}$ Campanha Oceanográfica foi realizada com o navio de pesquisa R/V GYRE, onde os profissionais embarcados ficaram responsáveis pela coleta das amostras.

A validação das amostras coletadas ficou sob a responsabilidade da equipe da UFS. Esta campanha oceanográfica teve duração de 14 dias e foi realizada de 24 de outubro a 07 de novembro de 2008.

Tabela 1 - Síntese das campanhas oceanográficas realizadas para a coleta de sedimentos.

\begin{tabular}{l|c|c|c|c}
\hline \multicolumn{1}{c|}{ Período } & $\mathbf{1}^{\mathbf{a}}$. Campanha & $\mathbf{2}^{\mathbf{a}}$. Campanha & $\mathbf{3}^{\mathbf{a}}$. Campanha & $\mathbf{4}^{\mathrm{a}}$. Campanha \\
\hline Região da plataforma & 2008 & $2010 / 2011$ & 2012 & 2013 \\
\hline Embarcação & $\begin{array}{c}\text { Sul Alagoas e norte de } \\
\text { Sergipe }\end{array}$ & $\begin{array}{c}\text { Sul Alagoas e } \\
\text { norte de Sergipe }\end{array}$ & Sul de Sergipe & Sul de Sergipe \\
\hline Transectos & Navio R/V GYRE & Vespúcio & Turista & Distrimar III \\
\hline Estações de amostragem & 1 ao 85 & 1 ao 85 & 87 ao 157 & 87 ao 157 \\
\hline Analises de Biodetritos $\left(\mathbf{n}^{\circ}\right.$ amostras) & 433 & 31 & 288 & 79 \\
\hline Tipo de amostrador & 173 & 0 & 204 & 46 \\
\hline
\end{tabular}

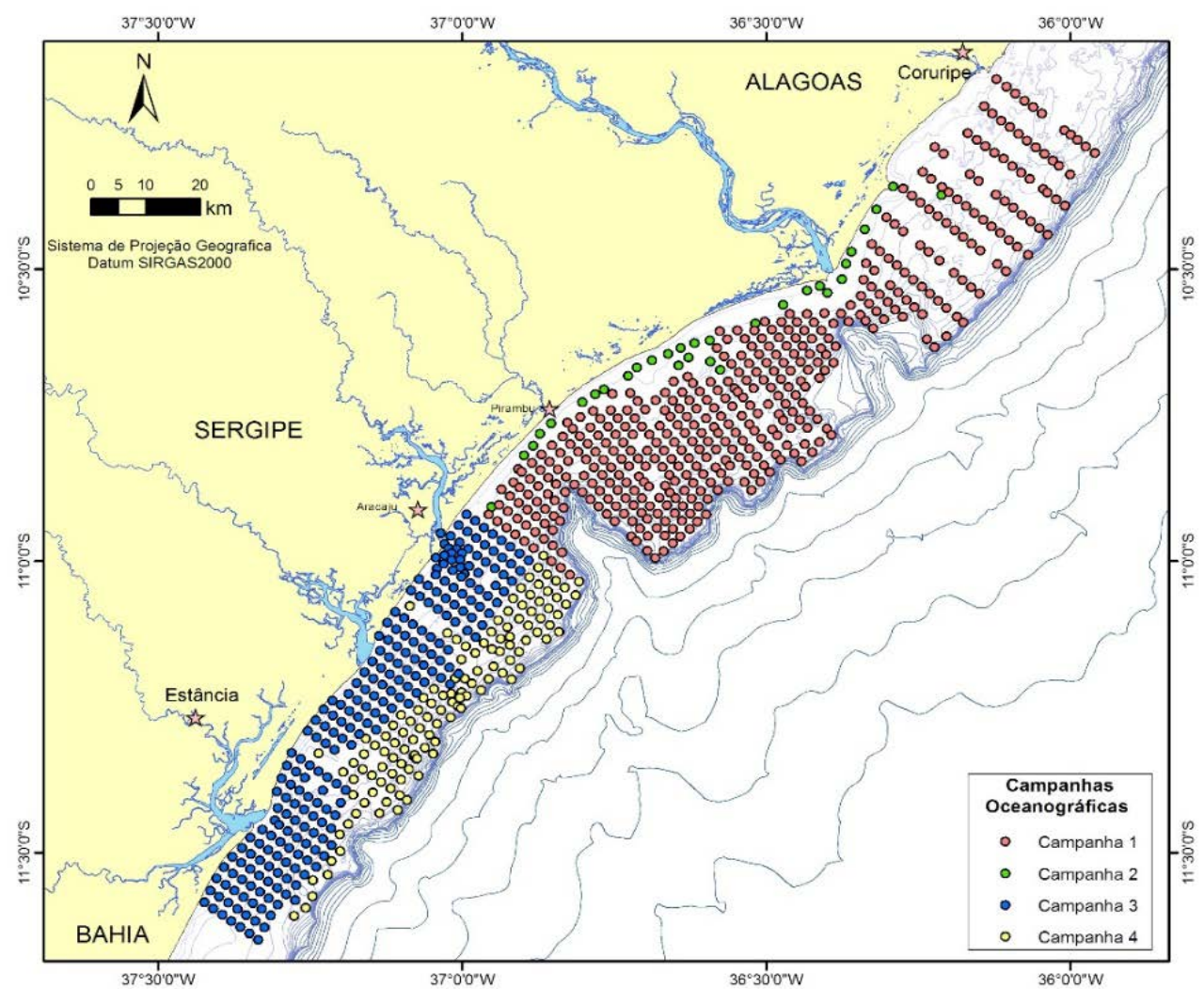

Figura 2 - Estações de amostragem de sedimento das companhas oceanográficas.

A $2^{\text {a }}$ campanha foi realizada entre 2010 e 2011, em várias etapas, entre a desembocadura do rio São Francisco e Japaratuba, na qual teve por objetivo principal detalhar a plataforma entre a costa e os $10 \mathrm{~m}$ de profundidade. Nesta campanha foram coletadas 31 amostras de sedimentos, porém foram analisados apenas a granulometria e teor de carbonato. 
A $3^{\mathrm{a}}$ e $4^{\mathrm{a}}$ campanhas oceanográficas também foram realizadas em etapas, nos anos 2012 e 2013, na plataforma continental sul de Sergipe, entre a foz do rio Sergipe e o município de Jandaíra - BA (Figura 2).

Na $1^{\text {a }}$ campanha oceanográfica, em função da diversidade de tipos de sedimentos no substrato plataformal foram utilizados dois tipos de amostradores de sedimentos de fundo, um do tipo Box Core e outro do tipo Van Veen (Figura 3). Nas demais campanhas utilizou-se apenas o amostrador de sedimento do tipo Van Veen em função da facilidade de operação do equipamento.

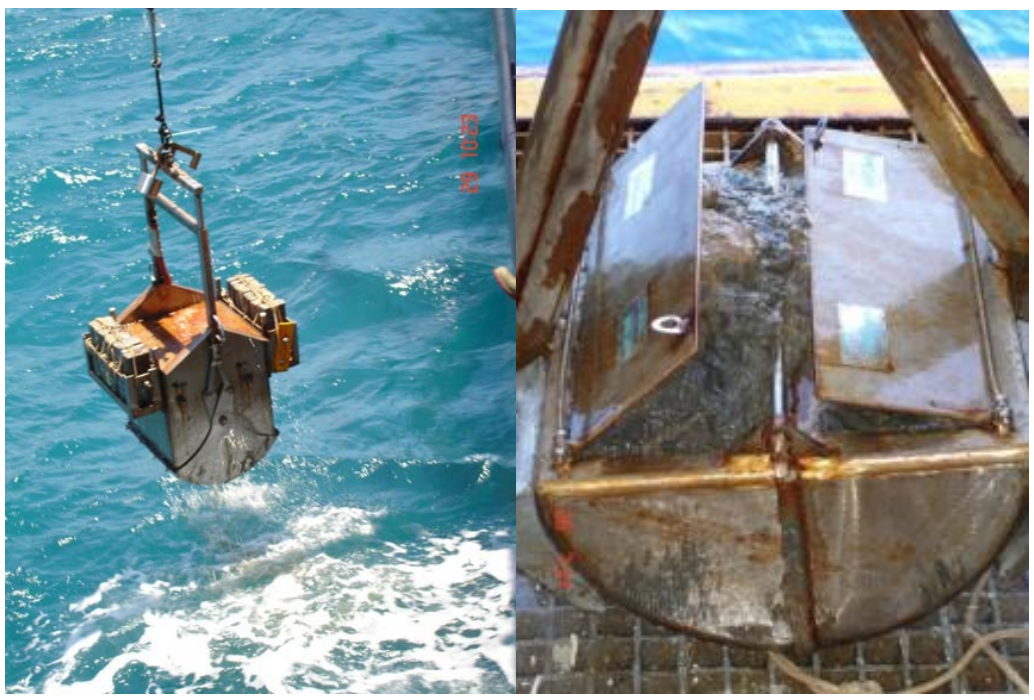

Figura 3 - Equipamentos de coleta de sedimentos: a) Box Core e b) Van Veen.

O amostrador tipo Box Core foi utilizado principalmente para amostragem de sedimentos finos (lamas) e o amostrador Van Veen para os sedimentos grosseiros (areias e cascalhos). As amostras foram coletadas, acondicionadas em sacos plásticos com aproximadamente $500 \mathrm{~g}$ de sedimentos e armazenadas em temperatura ambiente, com a identificação das amostras coletadas em cada estação, através de etiquetas internas e externas, contendo as informações de coleta: código da amostra, data, localização, profundidade, estrato e observações que se julgou necessárias.

\section{Processamento das Amostras}

As análises do conteúdo da composição e dos biodetritos foram realizadas em amostras de sedimentos superficiais de fundo, em 423 amostras de um total de 831 estações de amostragem localizadas em perfis transversais à linha de costa. A determinação dos componentes dos sedimentos foi efetuada em lupa binocular em duas frações granulométricas, obtidas através do processo de peneiramento mecânico: frações areia fina a média $(0,125$ a $0,250 \mathrm{~mm})$ e areia muito grossa a grânulo (1,00 a 2,82 mm).

Após a homogeneização de cada amostra, foram separados, de forma aleatória, 200 grãos para a análise composicional e de biodetritos, sendo 100 grãos para cada fração granulométrica, seguindo metodologia de Drooger \& Kaasschieter (1958).

Na etapa de processamentos dos dados, as percentagens de cada um dos grupos identificados foram ponderadas pelo peso de cada fração granulométrica, para determinação da contribuição de cada um destes componentes na amostra total. Os resultados obtidos foram expressos em planilha eletrônica, contendo para cada amostra, a abundância relativa (\%) da composição e dos biodetritos. Os resultados obtidos foram espacializados em mapas temáticos de distribuição.

Com esta base de dados e outras informações relativa à amostra de sedimento e do local amostrado, foi realizada correlações para a identificação de possíveis fatores ambientais (Tabela 2) que pudessem demonstrar variações ambientais com relação a distribuição sedimentar do fundo marinho. A partir da base de dados realizou-se uma análise para verificar a ocorrência dos componentes biogênicos para cada tipo de sedimento marinho de acordo com as classificações Shepard (1954) e Freire et al. (1997). Por critérios de definição foram considerados grãos carbonáticos os componentes incrustados por algas Rhodophyta e os agregados são os grãos de sedimento agrupados por uma película de cimento. 
Tabela 2 - Indicadores analisados para identificação de variações ambientais.

\begin{tabular}{l|l|l|c}
\hline \multicolumn{1}{c|}{ Indicador } & \multicolumn{1}{|c|}{ Atributos } & \multicolumn{1}{c|}{ Pergunta chave } & Método \\
\hline Profundidade & $\begin{array}{l}\text { Relação entre os componentes do } \\
\text { sedimento e a profundidade em } \\
\text { cada estação amostral }\end{array}$ & $\begin{array}{l}\text { Qual a relação entre a profundidade e a } \\
\text { distribuição dos componentes dos } \\
\text { sedimentos? }\end{array}$ & Correlação \\
\hline $\begin{array}{l}\text { Tipos de } \\
\text { sedimento }\end{array}$ & $\begin{array}{l}\text { Relação entre os componentes } \\
\text { biogênicos e a granulometria }\end{array}$ & $\begin{array}{l}\text { Qual a relação entre a composição } \\
\text { sedimentar e as características em cada } \\
\text { ponto amostral? }\end{array}$ & Correlação \\
\hline Biodiversidade & $\begin{array}{l}\text { Distribuição dos componentes } \\
\text { biogênicos do sedimento }\end{array}$ & $\begin{array}{l}\text { Como é a distribuição dos biodetritos em } \\
\text { toda a área amostral? }\end{array}$ & $\begin{array}{l}\text { Espacialização por } \\
\text { ponto amostral }\end{array}$ \\
\hline
\end{tabular}

\section{Classificação das Biofácies}

Para realizar a classificação das biofácies dos sedimentos de fundo, foram reunidos os dados da textura, faciologia e da distribuição dos componentes biogênicos, para posteriormente identificar o tipo sedimentar e os organismos predominantes do sedimento. Diversas são as metodologias de classificação de sedimentos propostas, como por exemplo, Shepard (1954), Folk \& Ward (1957), Larsonneur (1977), Dias (1996) e Freire et al. (1997) e Vital et al. (2005). Entretanto, neste estudo, a classificação da composição e textura dos sedimentos será com base numa adaptação de Folk (1954) e Rebouças (2010).

As classes de biofácies identificadas foram mapeadas de acordo com sua distribuição ao longo da plataforma, para verificar espacialmente a ocorrência de cada tipo de biofácies encontrada. Todos os dados sedimentológicos obtidos foram espacializados em um sistema de informação geográfica (SIG), no software ArcMap 10.0, aos quais foram adicionados dados batimetria e textura sedimentar, elaborando-se assim os mapas temáticos apresentados neste trabalho.

\section{RESULTADOS E DISCUSSÃO}

\section{Composição dos Sedimentos da Pcseal}

Foram identificadas seis categorias de componentes que fazem parte dos sedimentos da plataforma continental SEAL: grãos carbonáticos, biodetritos, quartzo, micas, fragmentos de rochas e agregados. Os componentes mais abundantes são os biodetritos (Figura 4), seguido do quartzo (Figura 5a), grãos carbonáticos (Figura 5b), agregados e outros (micas e fragmentos de rocha).
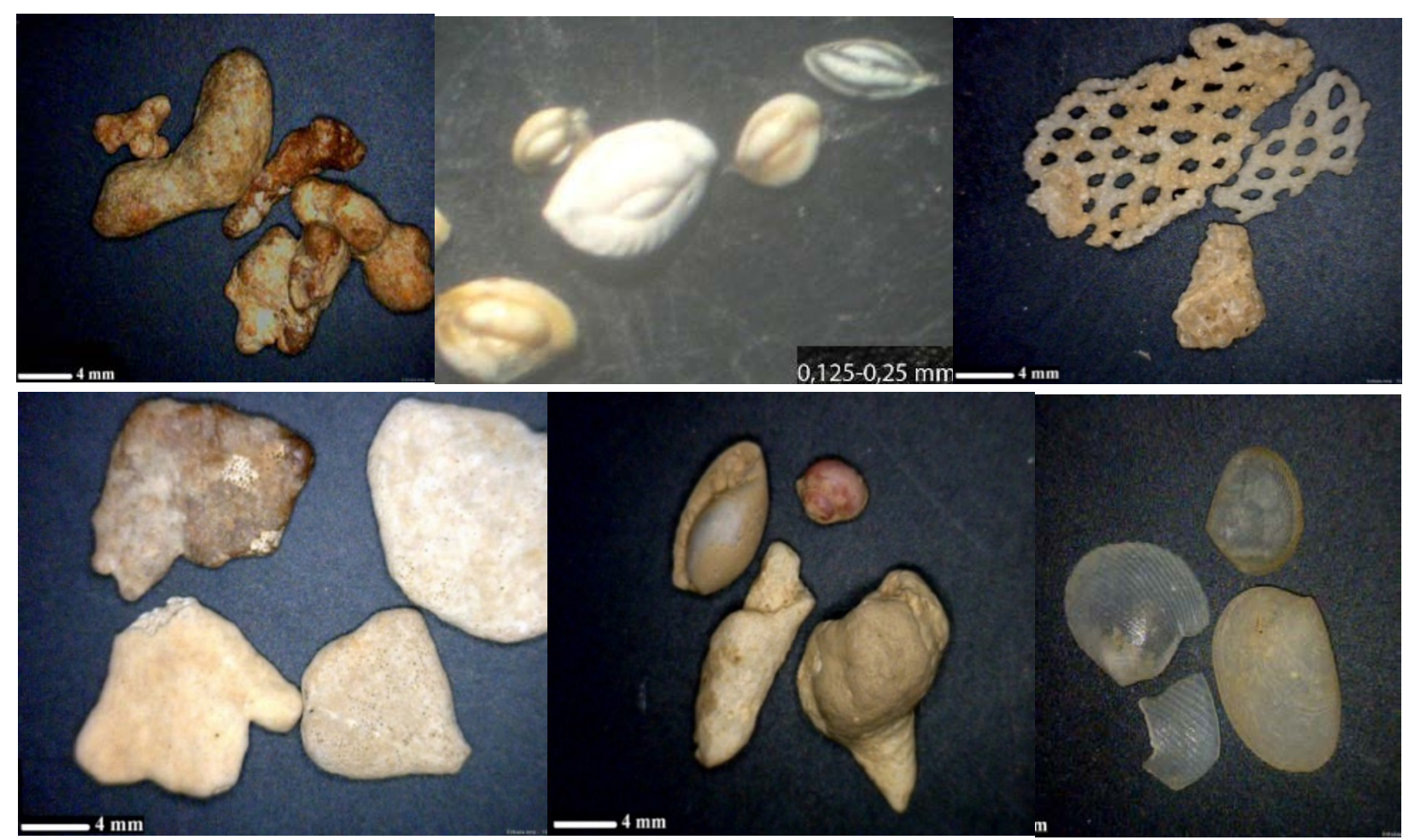

Figura 4 - Exemplares das amostras de Biodetritos: (a) Algas vermelhas; (b) Foraminífero; (c) Briozoários; (d) Halimeda; (e) Gastrópodes; (f) Bivalves. Fonte: Laboratório GOERIOEMAR -UFS. 


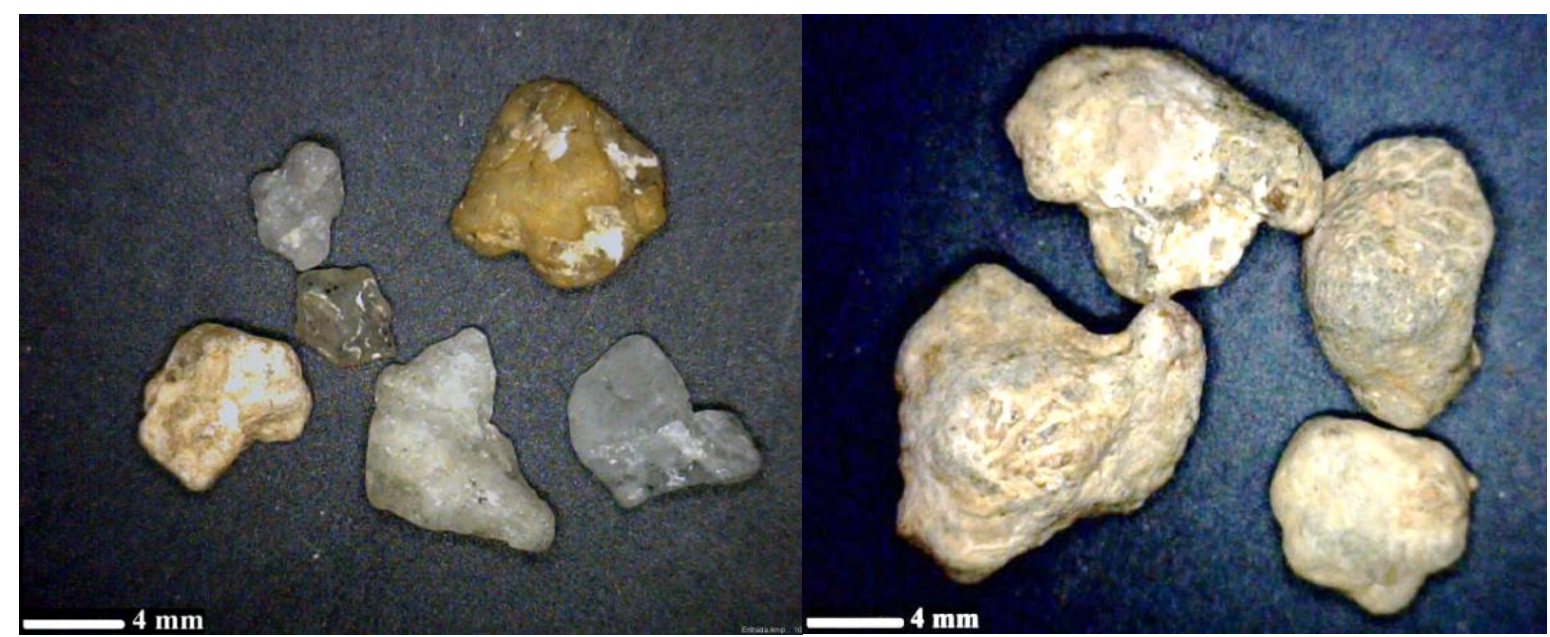

Figura 5 - Componentes encontradas na plataforma continental SEAL: a) grãos de Quartzo e b) grãos carbonáticos. Fonte: Laboratório GOERIOEMAR -UFS.

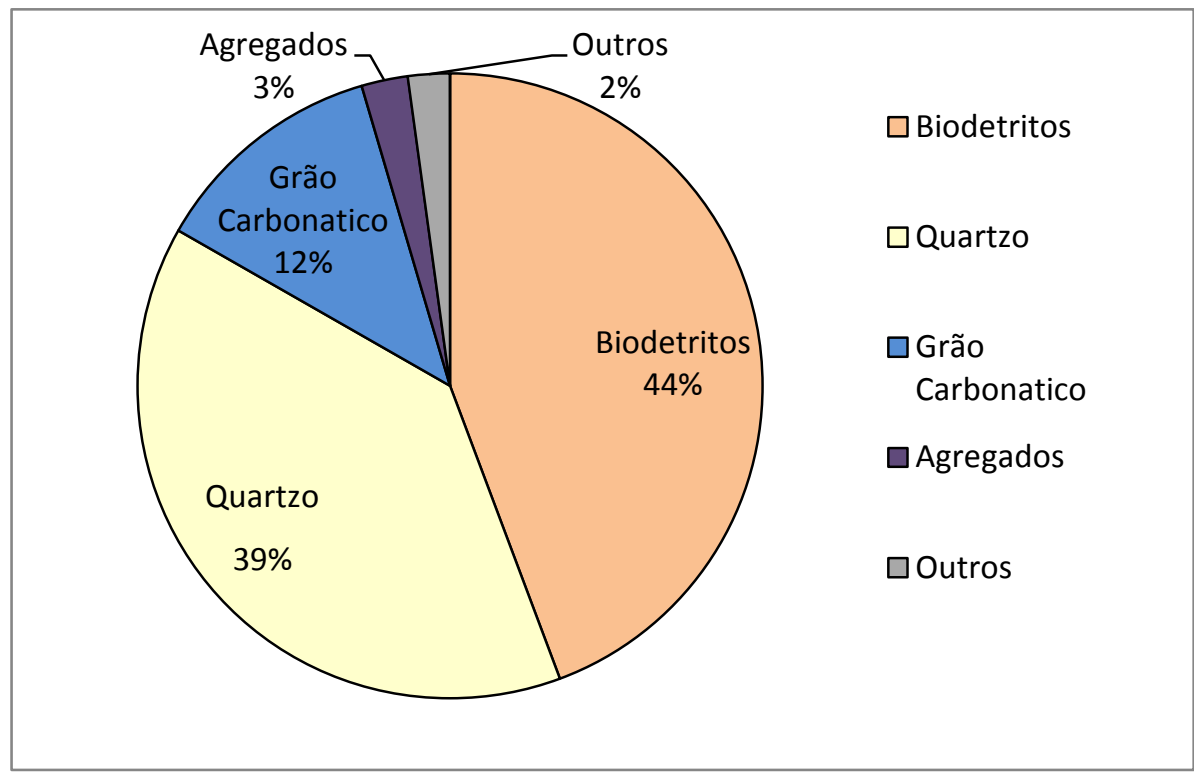

Figura 6 - Abundância relativa total da composição sedimentar na PCSEAL.

A figura 6 apresenta a abundancia relativa dos componentes na área estudada

A análise dos componentes biogênicos (Figura 4) dos sedimentos permitiu a identificação de 12 grupos taxonômicos de biodetritos nas seguintes categorias: Algas vermelhas (filo Rhodophyta); Algas verdes Halimeda (filo Chlorophyta); Foraminíferos (filo Rhizopoda); Equinodermos (espinhos e carapaças de ouriço - filo Echinodermata); Esponjas (espículas - filo Porifera); Fragmentos de crustáceos (filo Crustacea); Briozoários (filo Bryozoa); Gastrópodes, Bivalves, Escafópodes (filo Mollusca) e Vermetídeos (classe Gastropoda) e Corais (filo Cnidaria).

As faixas de domínios dos componentes dos sedimentos se apresentam de forma alinhada paralelamente e transversalmente com a linha de costa, ocorrendo uma transição da composição da região mais rasa para a mais profunda e também uma interrupção nas regiões lamosas ligadas ao rio São Francisco e Japaratuba (Figura 7). Os biodetritos e grãos carbonáticos predominam na plataforma média a externa (>30m) e o quartzo (sedimentos siliciclásticos) na plataforma interna a média.

Os componentes siliciclásticos (quartzo e fragmentos de rocha) se concentram principalmente ao longo da linha de costa, até aproximadamente a isóbata de 30 metros (Figura 7).

No restante da plataforma a fração grossa do sedimento é constituída dominantemente por bioclastos. Destes, os fragmentos de algas coralinas predominam nos setores médio e externo da plataforma, principalmente na borda da plataforma, e também em profundidades superiores a 25 metros. 


\section{Textura dos Sedimentos da Pcseal}

No período Quaternário, os rios São Francisco e Japaratuba foram responsáveis por elevado aporte de sedimentos que influenciaram diretamente a sedimentação da plataforma continental adjacente, estabelecendo uma clara diferenciação entre os setores ao norte e ao sul de suas desembocaduras, em função da deposição e distribuição dos sedimentos siliciclásticos de origem continental, formando duas grandes zonas de deposição lamosa na plataforma e os cânions submarinos que escavam a plataforma e o talude continental (Schreiner et al., 2015; Fontes, et al., 2017; Oliveira et al., 2017).

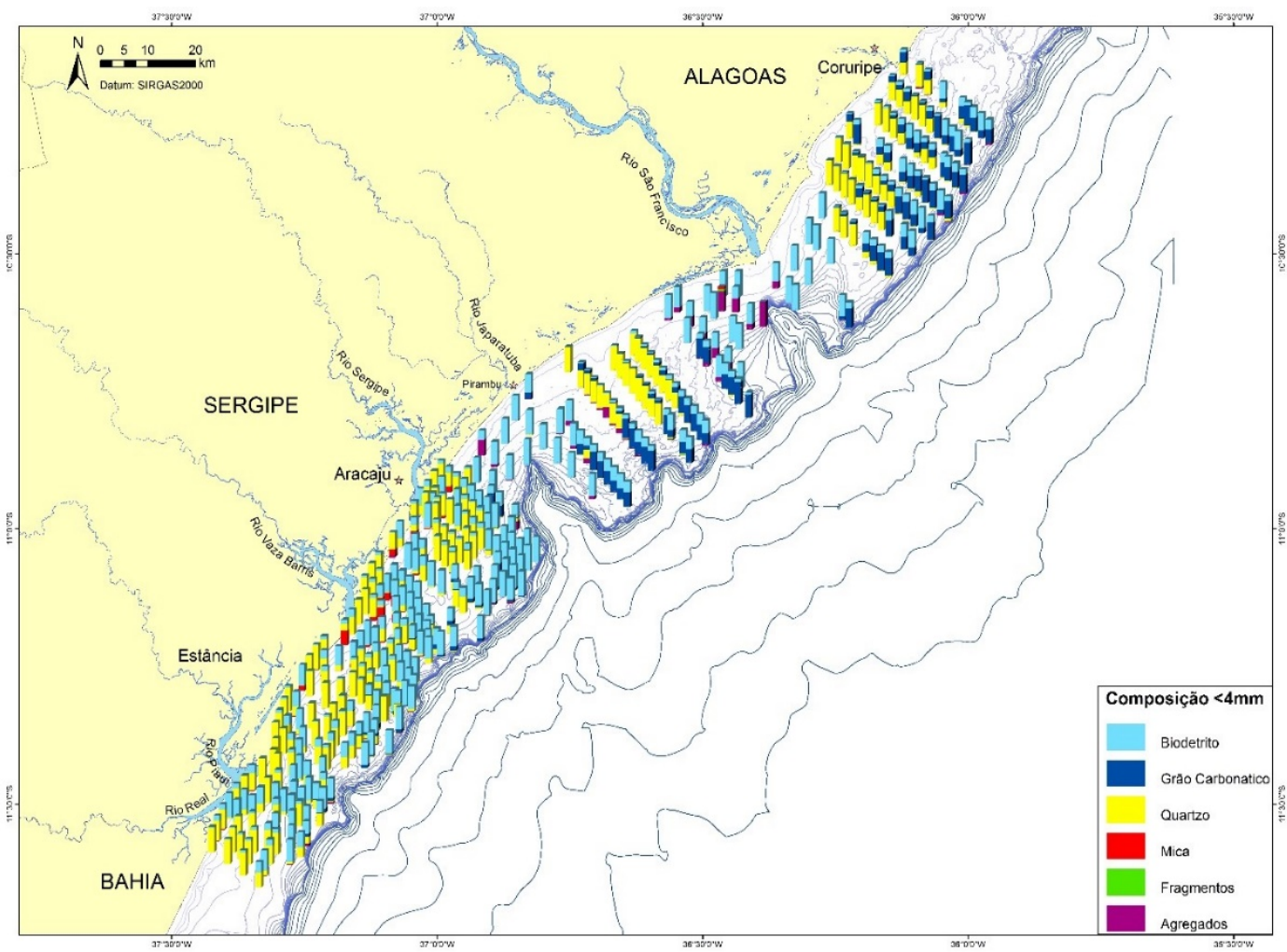

Figura 7 - Distribuição espacial da composição dos sedimentos na plataforma continental SEAL.

A fração areia apesar de distribuída ao longo de toda a plataforma predomina junto à linha de costa até a isóbata de $25 \mathrm{~m}$, com exceção da região do município de Coruripe, sul de Alagoas, onde predominam os cascalhos a partir da isóbata de $10 \mathrm{~m}$. A fração cascalho apresenta seus maiores teores na plataforma externa, com exceção nas zonas lamosas do São Francisco e Japaratuba.

A fração lama apresenta seus maiores teores nas regiões topograficamente rebaixadas, principalmente associadas às desembocaduras dos rios (Guimarães, 2010; Nascimento, 2011; Fontes et al., 2017).

\section{Distribuição dos teores de Carbonatos}

Os teores de carbonato se apresentam elevados na região da plataforma externa, desde o sul de Alagoas até o sul de Sergipe, onde atingem entre 70 a $100 \%$ do sedimento, sendo interrompidos pelos cânions submarinos do São Francisco e Japaratuba (Figura 8).

Os grãos carbonáticos e biodetritos predominam em profundidades maiores, ao longo de toda a margem da plataforma, sendo estes componentes os principais responsáveis pelas maiores ocorrências do teor de carbonatos na borda da plataforma, visto que a plataforma externa $(>30 \mathrm{~m})$ a região com condições ideais para o desenvolvimento de sedimentos biogênicos.Os menores teores de carbonatos e os maiores teores de matéria orgânica coincidem com as zonas lamosas associada aos rios São Francisco e Japaratuba e também às regiões de ocorrência de areias siliciclásticas. Porém, as zonas lamosas plataformais do sul de Sergipe apresentam teores elevados de carbonatos e grande abundância de biodetritos.

Os padrões da distribuição dos teores de carbonato refletem de modo geral a distribuição do cascalho, pois são constituídos principalmente por carbonatos. A plataforma de Alagoas é dominada por sedimentos carbonáticos biogênicos, como também, as regiões da plataforma externa entre os cânions do São Francisco e Japaratuba e a plataforma sul de Sergipe. 


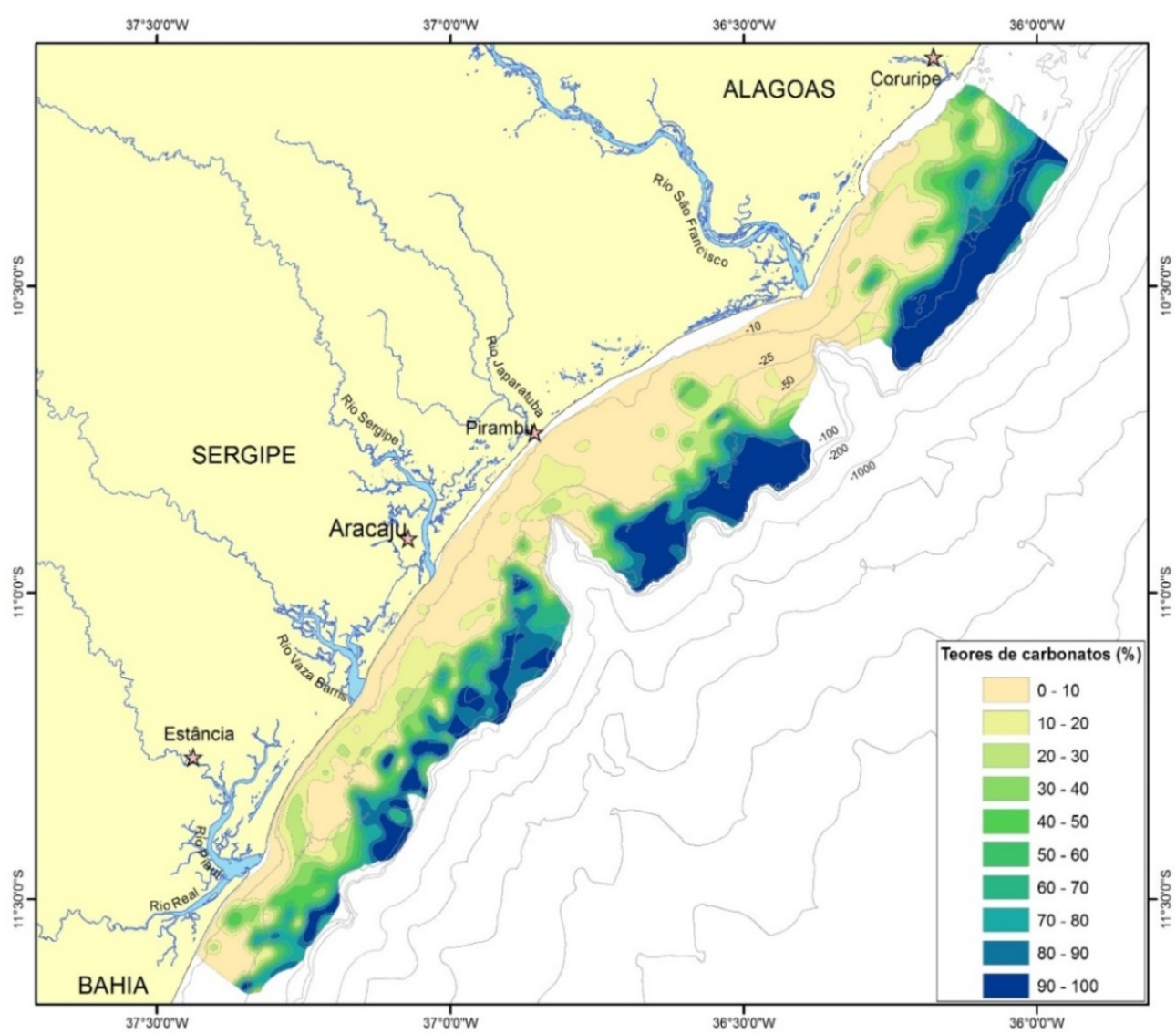

Figura 8 - Distribuição dos teores de carbonato na plataforma continental SEAL. Modificado de Fontes et al. (2017).

\section{Fácies Texturais}

Na plataforma continental SEAL ocorrem sete classes texturais sedimentares: Cascalho, Cascalho arenoso, Areia cascalhosa, Areia, Areia lamosa, Lama arenosa e Lama; e cinco classes de faciológicas (Figura 9): Bioclástica, Bio-siliciclásticas, Silici-bioclásticas, Siliciclástica arenosa e Siliciclástica lamosa (Fontes et al., 2017).

A fração cascalho, por ser essencialmente bioclástica, não reflete necessariamente os níveis de energia no ambiente, e $\operatorname{sim}$ a acumulação in situ das partes duras do esqueleto dos organismos marinhos.

A fácies Cascalho Bioclástica ocorre predominantemente na plataforma externa próximo a quebra da plataforma. As fácies Cascalho arenoso, Areia cascalhosa, Biosiliciclástica e Silici-bioclástica concentra-se principalmente na plataforma intermediária, entre os 25 e 30 metros de profundidade, na zona de transição entre os sedimentos de natureza continental (siliciclásticos) dos sedimentos marinhos (biogênicos).

As fácies Areia e a Siliciclástica arenosa predomina na plataforma, entre a linha de costa e os 25 metros de profundidade, sendo interrompidas pelas zonas lamosas. As fácies Areia Lamosa, Lama arenosa, Lama e Siliciclástica lamosa ocorrem nas zonas baixas, associadas principalmente a foz dos rios.

A plataforma continental de Sergipe apresenta duas grandes zonas lamosas, que são localizadas em frentes aos rios São Francisco e Japaratuba.

Na plataforma externa ocorrem alguns pontos isolados de ocorrência de lama, associados a depressões topográficas, com alto teor de carbonatos e podem ser definidos como fácies margas. Componentes Biogênicos

Os componentes mais abundantes são as algas vermelhas, foraminíferos, bivalves e briozoários que correspondem a $82 \%$ dos biodetritos da região estudada, os demais componentes biogênicos representaram apenas 18\%.

Os briozoários apresentaram teores significativos (Figura 10), com maiores porcentagens encontradas na plataforma intermediária.

A distribuição espacial dos biodetritos (Figura 10) mostra a tendência das algas vermelhas (lithothaminium) e algas verdes (Halimeda) de predominarem principalmente na borda da plataforma continental SEAL. 


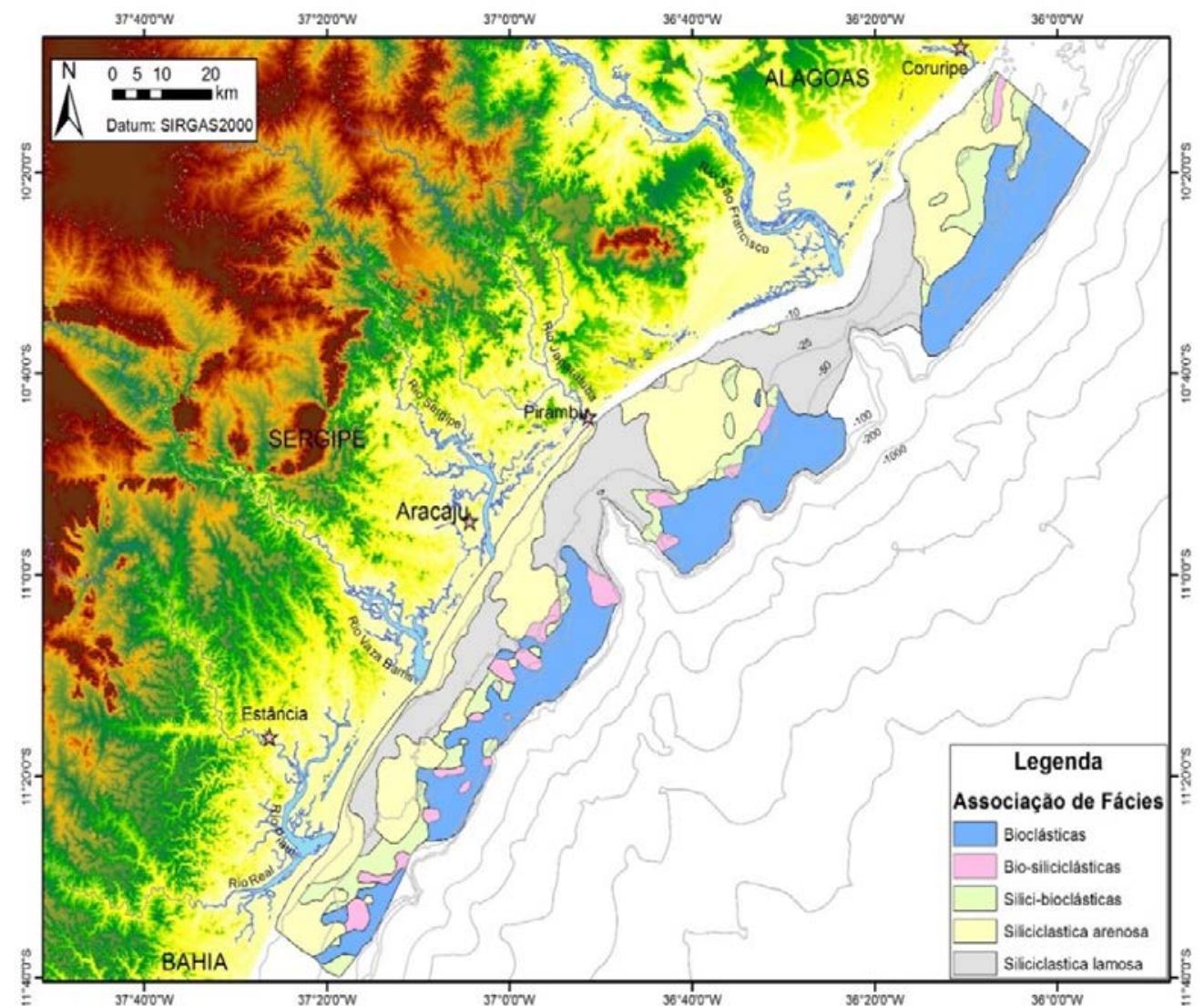

Figura 9 - Distribuição das classes faciológicas na plataforma SEAL. Modificado de Fontes et al. (2017).

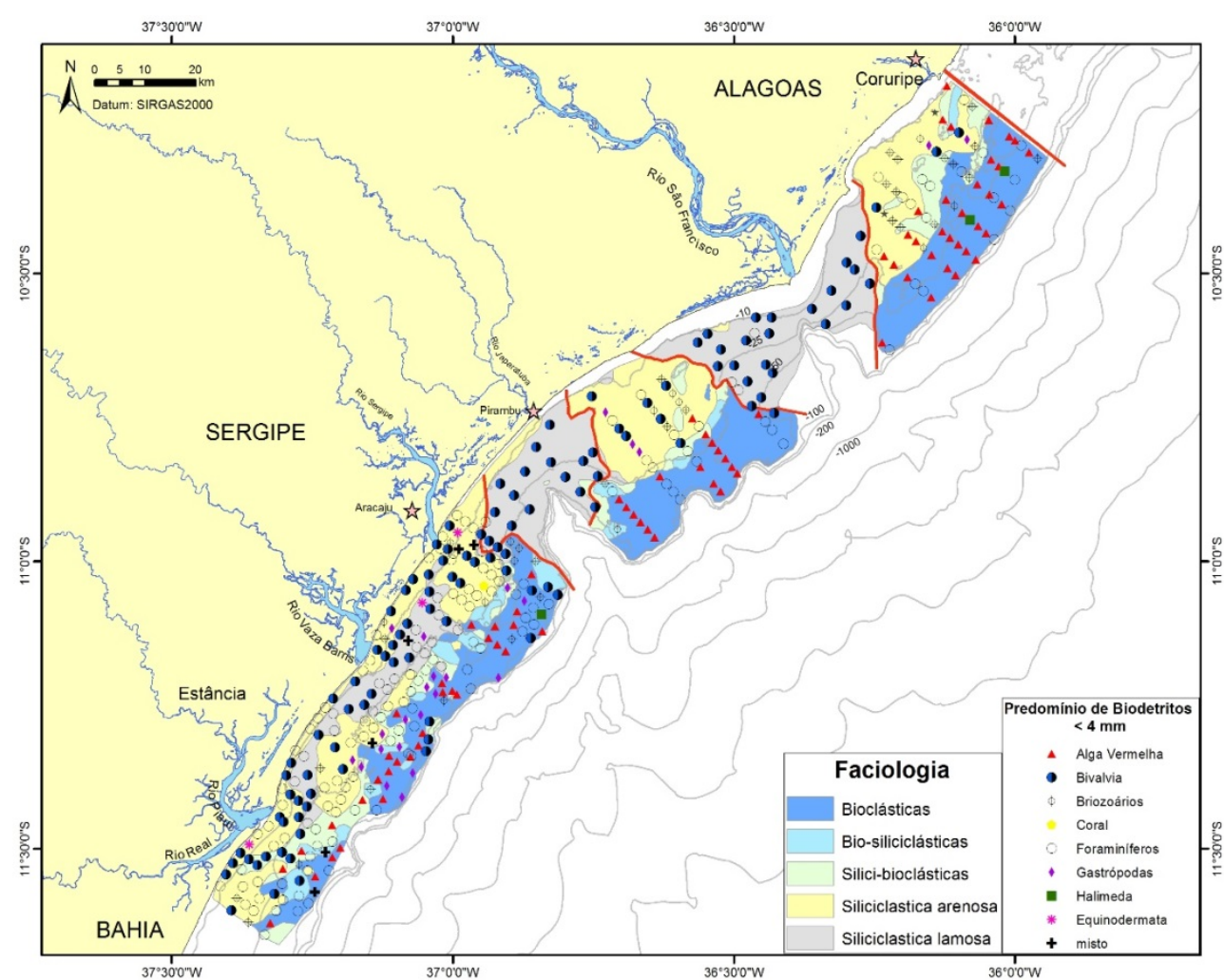

Figura 10 - Predomínio dos biodetritos nas estações de amostragem da PCSEAL.

A Halimeda é um gênero de algas verdes com talo calcificado que possui um importante papel ecológico e pode se acumular formando depósitos de sedimentos carbonáticos na plataforma continental nordeste do Brasil.
As Halimeda são limitadas aos trópicos e no Estado de Sergipe foram encontradas as espécies Halimeda discoidea, $H$. gracilis e $H$. opuntia (Bandeira-Pedrosa et al., 2004). A baixa ocorrência de Halimeda se deve principalmente 
a turbidez na região de influência do rio São Francisco, que é um fator limitante ao desenvolvimento das algas Halimeda, além da ausência de substratos adequados (Coutinho,1976).

Através da espacialização dos dados, pode ser verificado uma diferença quantitativa na abundância dos biodetritos, onde na zona lamosa do Japaratuba houve uma maior abundância dos biodetritos do que em relação a zona lamosa do São Francisco.

Os foraminíferos estão bem distribuídos ao longo da PCSEAL e ocorrem, na sua maioria, nas porções internas e intermediárias da plataforma e associados principalmente aos sedimentos da fração areia (sedimento Siliciclástico arenoso).

Entretanto, não foram realizadas as análises de identificação das espécies, impossibilitando a definição de formas bentônicas ou planctônicas, que permitiriam evidenciar seus modos de vida
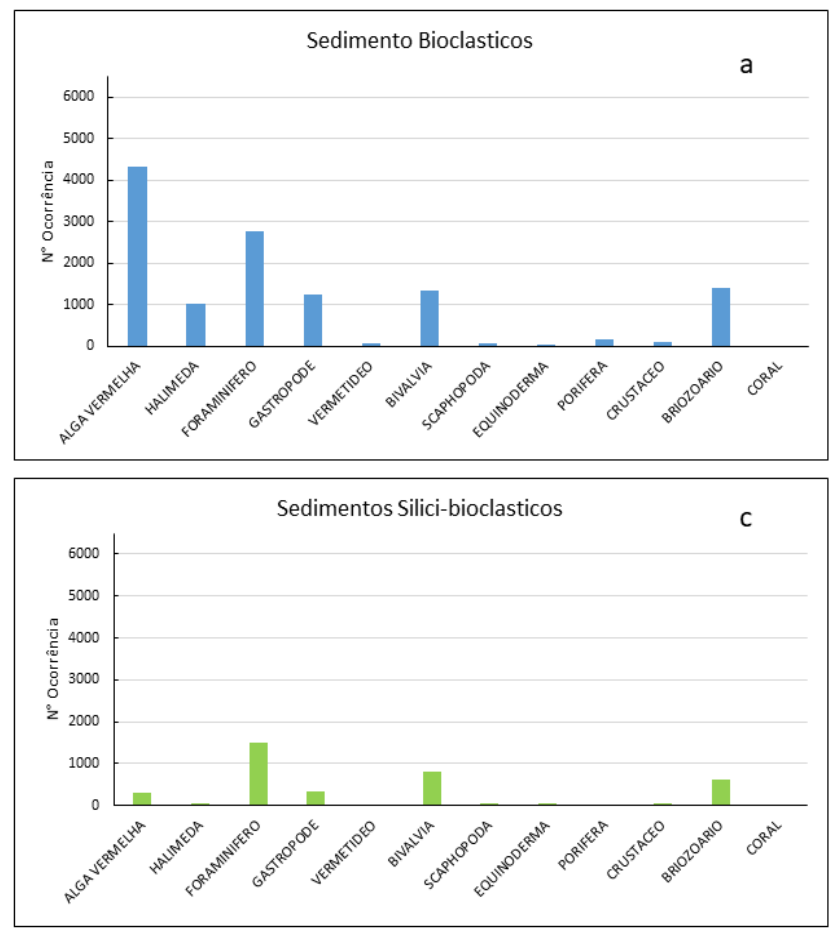

Figura 11 - Ocorrência dos biodetritos por tipo de sedimento a) sedimentos Bioclásticos b) sedimentos Biosiliciclásticos c) sedimentos Silici-bioclásticos d) sedimentos Siliciclásticos arenosos e lamosos.

Os componentes biogênicos, principalmente as algas coralinas, são amplamente dependentes dos fatores ecológicos, tais como: profundidade, luz, temperatura, salinidade, correntes, substrato, granulometria e fenômenos de competição (Coutinho, 1976, Costa, 2015). Embora possam ser estudados independentemente, devemos entender que estes fatores são inter-relacionados.

Os componentes biogênicos dos sedimentos e suas preferências ecológicas.

A análise entre a ocorrência dos componentes biogênicos e a granulometria evidenciou que as algas vermelhas e os foraminíferos são os principais componentes dos sedimentos bioclásticos (Figura 11a). Nos sedimentos mistos, Bio-siliciclásticos (Figura 11b) e Silici-bioclásticos (Figura 11c), os foraminíferos são dominantes, mas ocorrem associados com bivalves e briozoários. Os bivalves (Figura 11d) se concentram principalmente nos sedimentos siliciclásticos lamosos e em profundidades mais rasas $(>30 \mathrm{~m})$. A distribuição espacial dos principais componentes biogênicos encontrados por Nascimento (2011) na PCSEAL são as algas coralinas, os moluscos, os foraminíferos e os briozoários que totalizam $89 \%$ do total de grãos bioclásticos analisados, havendo uma conformidade com o presente trabalho, apesar da malha amostral ser diferente.
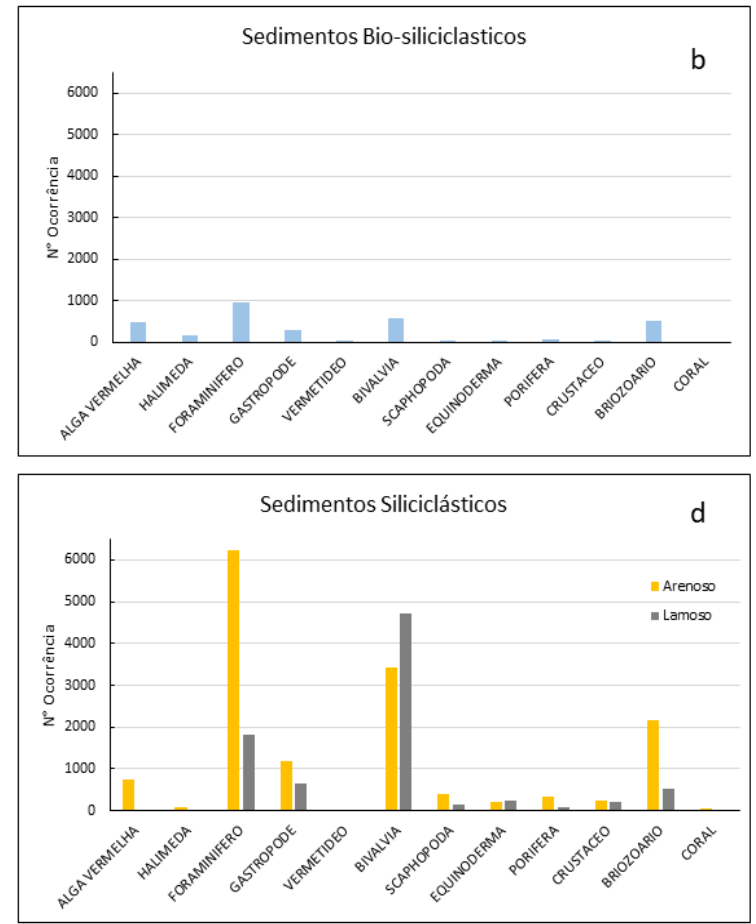

superficiais foram datados por carbono14 (Fontes et al., 2017), e três conjuntos de sedimentos com diferentes idades podem ser distinguidos.

Nos sedimentos da plataforma as idades correspondem até 570 anos AP (Holoceno). Enquanto, no cânion Japaratuba as idades variam entre 890 a 5300 anos AP. No cânion São Francisco as idades das carapaças são mais recentes, apresentando idades de percentagem 
do carbono moderno, indicando carapaças modernas. As diferenças na datação dos sedimentos biogênicos podem estar associadas ao ambiente de deposição, como também ao lento ou rápido revolvimento dos grãos na área estudada.

\section{Biofácies}

Foram identificadas 6 fácies sedimentares, de acordo com a distribuição da composição, textura e teor de carbonato dos sedimentos, baseado numa adaptação do sistema de classificação proposto por Folk (1954) e Rebouças (2010).

As fácies siliciclásticas (Figura 12) constituem-se em (i) areia quartzosa, distribuída na região da plataforma interna e intermediária; (ii) areia lamosa quartzosa com foraminífero e bivalve, distribuída ao longo da plataforma intermediária de toda área, geralmente entre as areias e as lamas; (iii) lama terrígena com bivalves, concentrada nas regiões baixas e associadas a foz dos principais rios. Estes sedimentos apresentam um teor de carbonato menor que $50 \%$.

As fácies bioclásticas (Figura 12) compõemse de (i) areia biodetrítica com foraminífero, distribuídas ao longo da plataforma intermediária e se estendendo em alguns pontos até a na quebra da plataforma; (ii) areia cascalhosa biodetrítica com alga coralina, foraminíferos e briozoários e (iii) cascalho arenoso biodetrítico com alga coralina ocorre principalmente na plataforma externa a partir da isóbata de $35 \mathrm{~m}$ até a quebra da plataforma. Estes sedimentos apresentam um alto teor de carbonato, geralmente maior que $50 \%$.

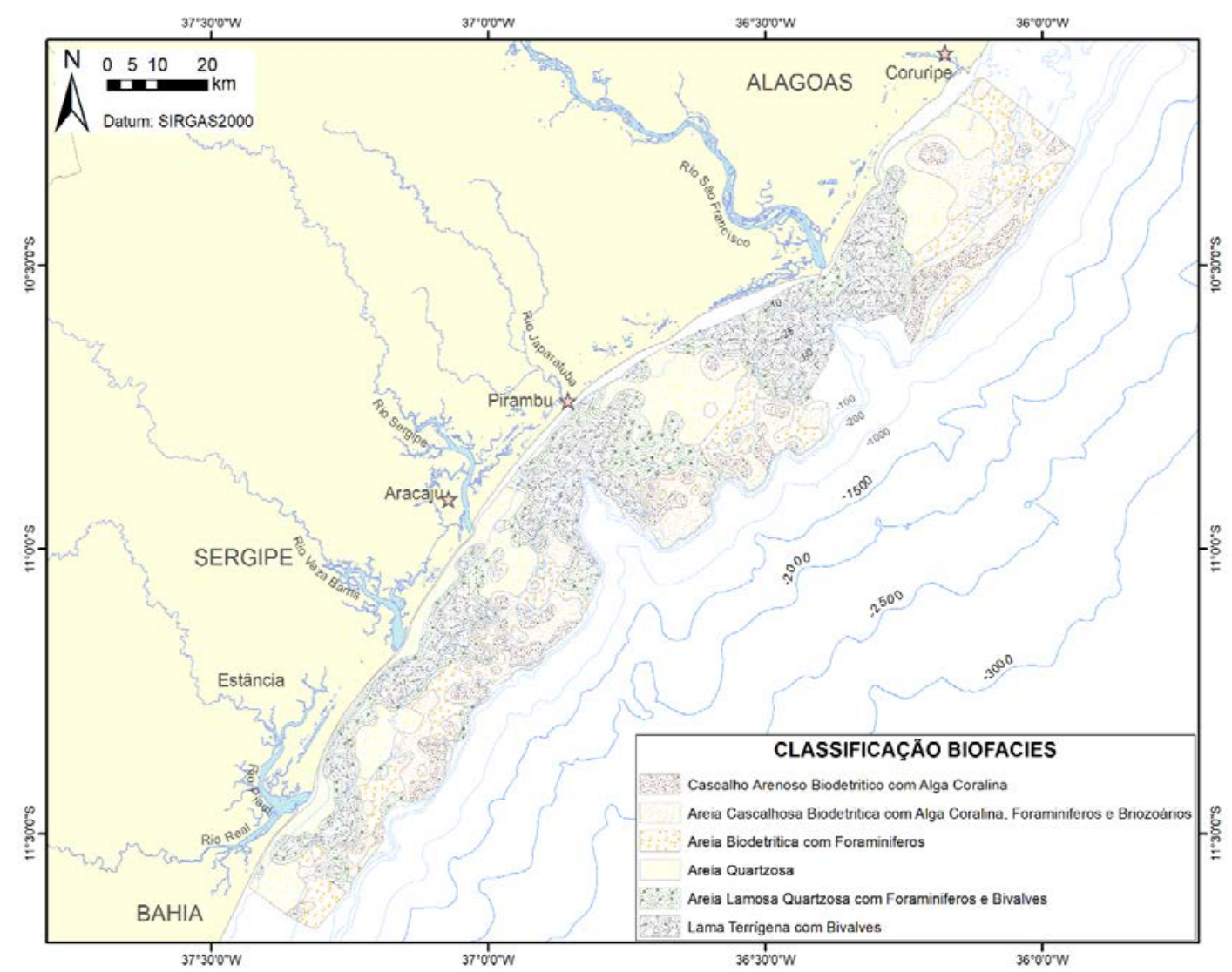

Figura 12 - Distribuição espacial das Biofácies ao longo da plataforma continental SEAL.

$\mathrm{Na}$ plataforma continental em frente a Salvador - BA, a distribuição dos componentes biogênicos e a distribuição das fácies bioclásticas é controlada pela presença de substratos duros e pela topografia, que condiciona a energia e os parâmetros físicos do ambiente, que por sua vez controlam a produção e a distribuição dos sedimentos biogênicos (Rebouças, 2010), assim como ocorre na plataforma continental SEAL.
A distribuição das associações carbonáticas foram propostas para as áreas tropicais e áreas temperadas (Lees, 1975; Carannante et al., 1988; Hayton et al., 1995). Na maior parte de plataforma continental SEAL predominam as associações do tipo foramol (formadas em sua maioria por foraminíferos e moluscos) ou heterozoan (compostas por organismos heterótrofos) (Westphal et al., 2010; Nascimento, 2011; Michel et al., 2018), 
característico de ambiente com disponibilidade de nutrientes e baixa luminosidade.

Os índices ecológicos permitem distinguir ambientes de acordo com a ocorrência das espécies. A diversidade tende a ser mais alta quanto maior o valor do índice Shannon \& Weaver (1964) e geralmente é o oposto da dominância. A equitatividade indica a estabilidade do sistema e baixos valores associam-se a baixos valores de diversidade e alta dominância. Os maiores índices de equitatividade traduzem a frequência semelhante das espécies (Boltovskoy \& Totah, 1985) e mostra a relação com a uniformidade da distribuição dos indivíduos entre as diferentes espécies (Clarke \& Warwick, 1994).

Através dos índices ecológicos (diversidade, dominância e equitatividade) é possível distinguir entre dois tipos de ambientes na PCSEAL. No primeiro ambiente, que constituem os sedimentos arenosos e cascalhosos, independente do teor de carbonatos, foi observado altos valores de diversidade (alto número de espécies), baixa dominância e baixo valor de equitatividade. No segundo ambiente, referente aos sedimentos lamosos, onde se tem a alta ocorrência dos bivalves, os índices expressam uma baixa diversidade, alta dominância e alta equitatividade.

\section{Ambientes Recifais}

Na plataforma continental SEAL constatou uma baixa presença de corais em relação à alta ocorrência de algas calcárias. O desenvolvimento dos corais ficou restrito aos substratos litificados, que podem representar antigas linhas de praias, arenitos ferruginosos provenientes da erosão do Grupo Barreiras ou estruturas de recifes algálicos, sendo que o crescimento atual dos corais ocorre principalmente no lado externo dos substratos litificados ou em construções de algas calcárias incrustantes (Manso et al., 2003; Bahia et al., 2010; Queiroz et al., 2016).

$\mathrm{Na}$ plataforma norte de Sergipe foram identificadas assembleias de corais zooxanthellate (Neves et al., 2005, 2006) no recife do Robalo, onde antes acreditava-se não haver ocorrências de corais. Isso desconstrói a ideia anterior que apontava o rio São Francisco como uma "barreira biológica", por ser o maior canal fluvial adentrando o Atlântico, entre o rio Amazonas e o rio de La Plata, impedindo o desenvolvimento de corais no Estado de Sergipe em função da sua grande carga de material em suspensão (Knoppers et al., 2006; Medeiros et al., 2007, 2011; Oliveira et al., 2012).

Apesar que nas condições atuais a descarga fluvial do rio São Francisco tem diminuído drasticamente, bem como o material em suspensão devido as barragens ao longo do rio (Fontes, 2015; Vasco et al., 2017).

O desconhecimento deste recife de corais tem contribuído para a disseminação errônea da concepção de que a área sob influência do rio São Francisco pode ser classificada como "zona desprovida de corais” (Neves et al., 2006).

As espécies de corais identificadas mostram a existência de espécies endêmicas do Brasil como a Siderastrea stellata e a Mussismilia híspida (Neves et al., 2005). A quantidade de espécies de corais Scleractinia registrada em Sergipe é uma evidência de considerável em uma área previamente considerada como inóspita para o estabelecimento e desenvolvimento de uma típica comunidade de corais.

\section{Controle Morfológico-Hidrodinâmico}

O sedimento de composição de quartzo apresenta uma distribuição inversa aos componentes biogênicos e também com a profundidade.

Comparado a profundidade das estações com a ocorrência do quartzo (Figura 13a) e também dos biodetritos (Figura 13b), verificou-se que os grãos de quartzo são mais predominantes em águas mais rasas enquanto os biodetritos ocorrem predominantemente em aguas mais profundas, sendo a profundidade de $30 \mathrm{~m}$ a zona de transição entre estes tipos de sedimento.

Nas regiões onde a hidrodinâmica é menor e nas regiões baixas, os baixos níveis de energia favorecem a acumulação de sedimentos lamosos, onde os componentes biogênicos principais são espécies de bivalves e foraminíferos.

Em contraposto a este padrão hidrodinâmico, é ao longo da linha de costa que encontramos os ambientes de maior energia. É justamente nos ambientes de maior energia, em função do efeito de ação de ondas e de correntes ou pela maior concentração de material em suspensão na coluna d'agua, em função dos aportes continentais, que se verificam as maiores ocorrências de componentes siliciclásticos no sedimento superficial. Estes ambientes altamente 

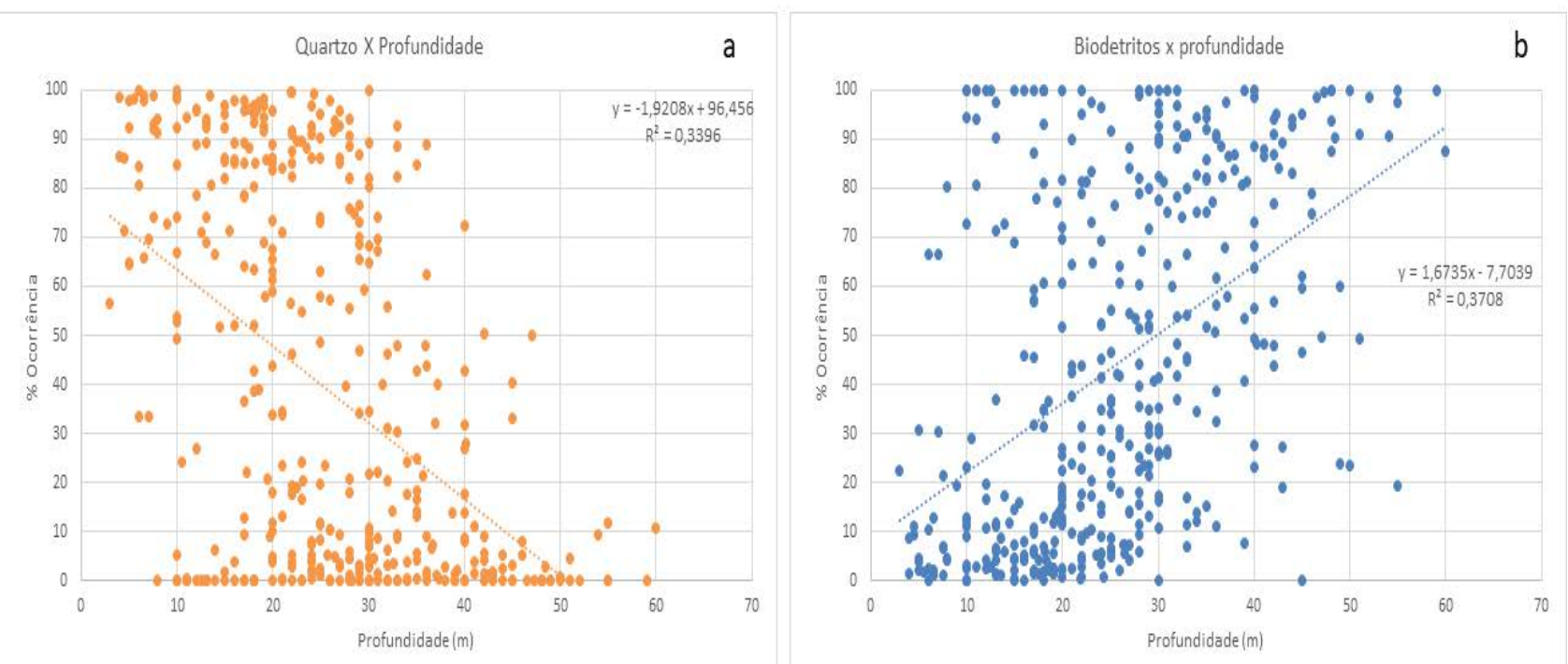

Figura 13 - Correlação da ocorrência dos grãos de quartzo (a) e dos biodetritos (b) com a profundidade das estações de amostragem.

energéticos são mais hostis aos organismos marinhos, resultando na ausência de componentes bioclásticos (algas vermelhas e halimedas) no sedimento.

A plataforma externa possui condições propícias ao desenvolvimento de algas coralinas Rhodophyta (algas vermelhas) e Chlorophyta (algas verdes) devido à combinação da temperatura e salinidade elevadas, plataforma rasa e o alcance da zona fótica, até 50-60 m de profundidade, baixa turbidez, corrente de fundo e de substratos rígidos para a incrustação das algas, favorecendo uma sedimentação bioclástica com predominância de fragmentos de algas coralinas e secundariamente foraminíferos.

Os principais componentes biogênicos nas praias do sul de Alagoas são as conchas de moluscos e fragmentos de algas vermelhas e Halimeda (Vieira \& Manso, 2017). O padrão de distribuição dos sedimentos sugere que, além dos grãos oriundos do continente, a plataforma continental constitui uma importante fonte de sedimentos para as praias (Rebouças et al. 2011; Vieira \& Manso, 2017).

Verificou-se que a distribuição de associações de organismos bióticos obedece ao zoneamento longitudinal e ao zoneamento transversal no sentido litoral-oceano, à penetração da luz, à hidrodinâmica ambiental, aos processos sedimentares dominantes, ao tipo de substrato e à morfologia de fundo, como também observado em outras plataformas (Rebouças, 2010, Costa, 2015).

\section{CONCLUSÕES}

A plataforma continental SEAL é do tipo mista siliciclástica-carbonática. Os componentes biogênicos são constituídos principalmente por foraminíferos, algas vermelhas e briozoários, que são responsáveis pela formação de um banco carbonático na plataforma externa. A fração cascalho é composta predominantemente por algas vermelhas.

As principais fontes de sedimento para os depósitos sedimentares na plataforma continental de Sergipe correspondem ao material trazido em suspensão pelos rios; aos antigos depósitos subaéreos de areias (relíquias); e a produção de carbonatos in situ pelos organismos.

Conclui-se a existência de uma nítida transição da composição sedimentar com o aumento da profundidade, onde em regiões mais rasas têm-se o predomínio de sedimentos de origem continental (alóctones) e em regiões mais profundas sedimentos biogênicos (autóctones), entretanto, esta característica é interrompida pelas zonas lamosas do São Francisco e Japaratuba.

Associações do tipo foramol ou heterozoan predominam na maior parte de plataforma, indicando um ambiente rico em nutrientes e de baixa luminosidade.

As diferenças na idade dos sedimentos biogênicos podem estar associadas ao ambiente de deposição, como também a remobilização e transporte dos grãos na área.

Desta maneira, a distribuição dos sedimentos biogênicos na plataforma continental SEAL 
resulta de um ajuste morfodinâmico entre a circulação e a topografia da plataforma.

Os índices ecológicos distinguiram dois tipos de ambientes na PCSEAL. No primeiro ambiente, que constituem os sedimentos arenosos e cascalhosos, independente do teor de carbonatos, foi observado altos valores de diversidade, baixa dominância e baixo valor de equitatividade. No segundo ambiente, referente às zonas lamosas, ocorre baixa diversidade, alta dominância e alta equitatividade.

\section{AGRADECIMENTOS}

Agradecemos a Petrobras através do Centro de Pesquisas - CENPES, pelo financiamento dos projetos de pesquisa intitulados "Projeto Caracterização geológica da plataforma continental e da influência dos aportes fluviais na região norte do Estado de Sergipe e sul do Estado de Alagoas" (Termo de Cooperação PETROBRÁS/UFS/FAPESE - N 0050.0045002.08.4) e do "Projeto de Caracterização dos Foraminíferos e Meiofauna da Plataforma continental de Sergipe e Sul de Alagoas e da Geologia-Geomorfologia da Plataforma Continental Sul de Sergipe” (Termo de Cooperação PETROBRAS/UFS/FAPESE - $\mathrm{N}^{\circ}$ 0050.0072321.119), que possibilitaram o levantamento das dados. À Universidade Federal de Sergipe, através do laboratório GEORIOEMAR e ao Programa de Pós-Graduação em Desenvolvimento e Meio Ambiente PRODEMA por toda a infraestrutura necessária para a realização da pesquisa. À Coordenação de Aperfeiçoamento de Pessoal de Nível Superior (CAPES), pela concessão de bolsa de doutorado ao primeiro autor.

\section{REFERÊNCIAS}

ALVE, E. Benthic foraminifera in sediment cores reflecting heavy metal pollution in Sorfjord, Western Norway: Journal of Foraminiferal Research, v. 21, p. 1-19. 1991.

ALVE, E. Benthic foraminiferal responses to estuarine pollution: a review: Journal Foraminiferal Research, v. 25, p. 190-203. 1995.

BAHIA, R.G.; ABRANTES, D.P.; BRASILEIRO, P.S.; PEREIRA-FILHO, G.H.; AMADO FILHO, G.M. Rhodolith bed structure along a depth gradient on the northern coast of Bahia State, Brazil. Brazilian Journal of Oceanography, v. 58, p. 323-337, 2010.

BANDEIRA-PEDROSA, M.E.; PEREIRA, S.M.B.; OLIVEIRA, E.C. Taxonomy and distribution of the green algal genus Halimeda (Bryopsidales, Chlorophyta) in Brazil. Rev. Bras. Bot., São Paulo, v. 27, n. 2, p. 363-377, 2004.

BERGUE, C.T. \& COIMBRA, J.C. Late Pleistocene and Holocene bathyal ostracodes from the Santos Basin, southeastern Brazil. Palaeontographica. Abteilung A: Palaozoologie - Stratigraphie. Stuttgart, v. 285, n. 4, p. 101144, 2008.

BITTENCOURT, A.C.S.P.; DOMINGUEZ, J.M.L.; FONTES, L.C.S.; SOUSA, D.L.; SILVA, I.R.; SILVA, F.R. Wave Refraction, River Damming, and Episodes of Severe Shoreline Erosion: The Sao Francisco River Mouth, Northeastern Brazil. Journal of Coastal Research, v. 23, n. 4, p. 930-938, 2007.

BOLTOVSKOY, E. \& TOTAH, V. Diversity, similarity and dominance in benthic foraminiferal fauna along one transect of the Argentine shelf. Revue Micropaleontologie, v. 28, n.1, p. 23-31, 1985.

CARANNANTE, G.; ESTEBAN, M.; MILLIMAN, J.D.; SIMONE, L. Carbonate lithofacies as palaeolatitude indicators: problems and limitations. Sedimentary Geology, v. 60, p. 333-346, 1988.

CHESF-COMPANHIA HIDRO ELETICA DO SÃO FRANCISCO. Disp. em: www.chesf.gov.br. Acesso em 30 agosto de 2018.

CLARKE, K.R. \& WARWICK, R.M., Change in Marine Communities: An Approach to Statistical Analysis and Interpretation. Plymouth: Plymouth Marine Laboratory, 144 p., 1994.

COSTA, R.O.L. Foraminíferos, ostracodes e microfauna associada da plataforma continental equatorial norte- riograndense, NE Brasil: área Porto do Mangue a Galinhos. Dissertação (Mestrado em Geodinâmica e Geofísica). Centro de Ciências Exatas e da Terra Universidade Federal do Rio Grande do Norte.

COUTINHO, P.N. Geologia marinha da plataforma continental Alagoas-Sergipe. Recife, 112p. 1976. Tese (Livre docência) - Centro de Tecnologia - Universidade Federal de Pernambuco.

COUTINHO, P.N. Oceanografia Geológica. In: Coutinho, P. N. ed. Levantamento do Estado da Arte da Pesquisa dos Recursos Vivos Marinhos do Brasil. Brasília, Ministério do Meio Ambiente dos Recursos Hídricos e da Amazônia Legal, Secretaria de Coordenação dos Assuntos do Meio Ambiente. (Programa REVIZEE). 75 p., 2000.

DIAS, G.T.M. Classificação de sedimentos marinhos, proposta de representação em cartas sedimentológicas. In: CONGRESSO BRASILEIRO DE GEOLOGIA, 39; Salvador. Anais... Salvador: Sociedade Brasileira de Geologia, 1996, v. 3, p. 423-426, 1996.

DIAS, J.A.A. Análise sedimentar e o conhecimento dos sistemas marinhos: uma introdução à oceanografia geológica. Universidade do Algarve, Faro. 2004. Disp. em http://w3.ualg.pt/ jdias/JAD/.

DROOGER, C.W. \& KAASSCHIETER, J.P.H. Foraminifera of the Orinoco Trinidad Paria shelf. Reports of the Orinoco Shelf Expedition. Vol. IV. N.V. Noord Hollandsche Uitgevers Maatschappj. Amsterdan, 108 p., 1958.

EICHLER, P.P.; EICHLER, B.B.; GUPTA, B.S.; RODRIGUES, A.R. Foraminifera as indicators of marine pollutant contamination on the inner continental shelf of southern Brazil: Marine Pollution Bulletin, v. 64, p. 22-30, 2012.

EMERY, K.O. Relict sediments on continental shelves of the world. American Association of Petroleum Geologists Bulletin, v. 52, p. 445-464, 1968.

FOLK, R.L. The distinction between grain size and mineral composition in sedimentary-rock nomenclature. Journal of Geology, v. 62, n. 4, p. 344-359, 1954.

FOLK, R.L. \& WARD, W.C. Brazos River bar: a study in the significance of grain size parameters. Journal of Sedimentary Petrology, v. 27, p. 3-26, 1957.

FONTES, L.C.S. Da Fonte à Bacia: Interação Continente- 
Oceano no Sistema Sedimentar Rio São Francisco, Brasil. Rio Claro - SP, 2015. 311p. Tese (Doutorado em Geociências) - Instituto de Geociências e Ciências Exatas, UNESP.

FONTES, L.C.S.; SANTOS, J.R.; SANTOS, L.A.; MENDONCA, J.B.S.; SANTOS, M.S. Sedimentos Superficiais da Plataforma Continental de Sergipe -Alagoas. In: FONTES, L.C.; KOWSMANN, R.O.; PUGABARNABÉU, A. (Ed.). Geologia e geomorfologia da Bacia de Sergipe-Alagoas. $1^{\text {a }}$ ed. São Cristóvão: Editora UFS, cap. 3. v. 1, p. 62-96. 2017.

FREIRE, G.S.S.; CAVALCANTI, V.M.M.; MAIA L.P.; LIMA, S.F. Classificação dos Sedimentos da Plataforma Continental do Estado do Ceará. In: SIMPÓSIO DE GEOLOGIA DO NORDESTE; 1997. Anais...Fortaleza: Sociedade Brasileira de Geologia, 1997, p. 209-211

GUIMARÃES, C.R.P. Composição e distribuição dos sedimentos superficiais e da fauna bêntica na plataforma continental de Sergipe. Salvador-Bahia. 2010. 159 p. Tese (Doutorado em Geologia), Instituto de Geociências Universidade Federal da Bahia.

HAYTON, S.; NELSON, C.S.; HOOD, S.D.A. Skeletal assemblage classification system for non-tropical carbonate deposits based on New Zeland and Cenozoic limestones. Sedimentary Geology, v. 100, p. 123-141, 1995.

KNOPPERS, B.A.; MEDEIROS, P.R.P.; SOUZA, W.F.L.; JENNERJAHN, T. The São Francisco Estuary, Brazil. In: WANGERSKY, J.P. (Ed.). The Handbook of Environmental Chemistry. Berlin-Heidelberg: SpringerVerlag, v.5, Part H, p. 51-70, 2006.

LARSONNEUR, C. La cartographie des depot meubles sur le plateau continental francais: methode mise au point et utilisee en manche. J. Rech. Oceanogra, v. 2, p. 34-39, 1977.

LEÃO, Z.M.A.N. \& MACHADO, A.J. Variação de cor dos grãos carbonáticos de sedimentos marinhos atuais. Revista Brasileira de Geociências, v. 19, n. 1, p. 87-91, 1989.

LEES, A. Possible influence of salinity and temperature on modern shelf carbonates sedimentation. Marine Geology, v. 19, p. 159-198, 1975.

LORENZO, N. \& VERDE, M. Estructuras de bioerosión em moluscos marinos de la formación Villa Soriano (Plaistoceno Tardío-Holoceno) de Uruguay. Revista Brasileira de Paleontologia. v. 7. n. 3. p. 319-328, 2004.

MANSO, V.A.V.; CORRÊA, I.C.S.; GUERRA, N.C. Morfologia e sedimentologia da plataforma continental interna entre as praias de Porto de Galinhas e Campos - litoral sul de Pernambuco, Brasil. Pesquisas em Geociências, v. 30, n. 2, p. 17-25, 2003.

MEDEIROS, P.R.P.; KNOPPERS, B.A.; SANTOS, R.C.; SOUZA, W.F.L. Aporte fluvial e dispersão de matéria particulada em suspensão na zona costeira do rio São Francisco (SE/AL). Geochimica Brasiliensis, v. 21, n. 2, p. 212-231, 2007.

MEDEIROS, P.R.P.; KNOPPERS, B.A.; SOUZE, W.F.L.; OLIVEIRA, E.N. Aporte de material em suspensão no baixo rio São Francisco (SE/AL) em diferentes condições hidrológicas. Braz. J. Aquat. Sci. Technol., v.15, n.1, p.4253, 2011.

MICHEL, J.; BORGOMANO, J.; REIJMER, J.J.G. Heterozoan carbonates: When, where and why? A synthesis on parameters controlling carbonate production and occurrences, EarthScience Reviews, v. 182, p. 50-67, 2018, ISSN 0012-8252, https://doi.org/10.1016/j.earscirev.2018.05.003.

MILLIMAN, J.D. Upper continental margins sedimentation off Brazil: Part VI. A synthesis. Contrib. Sedimentol., v. 4. p. 151-176, 1975.

MUTTI, M. \& HALLOCK, P. Carbonate systems along nutrient and temperature gradients: some sedimentological and geochemical constrains. International Journal of Earth Sciences, v. 92, p. 465-475, 2003.

NASCIMENTO, A.A. Sedimentação holocênica na plataforma continental de Sergipe, nordeste do Brasil. Salvador - Bahia. 2011. 105 p. Dissertação (Mestrado em Geologia). Instituto de Geociências - Universidade Federal da Bahia.

NEVES, E.G.; JOHNSSON, R.; SAMPAIO, C.L. An Unexpected Coral Assemblage in Submerged Reefs of the Sergipe State. In: CONGRESSO BRASILEIRO DE OCEANOGRAFIA, II, Vitória. Resumo Expandidos... Vitória, 2005.

NEVES, E.; JOHNSSON, R.; SAMPAIO, C.; PICHON, M. The occurrence of Scolymia cubensis in Brazil: revising the problem of the Caribbean solitary mussids. Zootaxa, v. 1366, p. 45-54, 2006.

NICOLAIDIS, D.D. Ostracodes de águas profundas do Pleistoceno/Holoceno da bacia de Campos: isótopos estáveis de oxigênio vs. mudanças faunísticas. Dissertação (Mestrado em Geociências) Porto Alegre - RS. 66p. 2008. Instituto de Geociências - Universidade Federal do Rio Grande do Sul.

OLIVEIRA, E.N.; KNOPPERS, B.A.; LORENZZETTI, J.A.; MEDEIROS, P.R.P.; CANEIRO, M.E.; SOUZA, W.F.L. A satellite view of riverine turbidity plumes on the NE-E Brazilian coastal zone. Brazilian Journal of Oceanography, São Paulo, v. 60, n. 3, p. 283-298, 2012.

OLIVEIRA JR., E. A. KOWSMANN, R.O.; SCHREINER, S.; FERREIRA, E.T.I. Geomorfologia do talude da Bacia de Sergipe-Alagoas. In: FONTES, L.C.S.; KOWSMANN, R.O.; PUGA-BERNABÉU, Á. (Ed.). Geologia e Geomorfologia da Bacia de Sergipe-Alagoas. São Cristóvão: Ed. UFS, cap. 4, p. 97-136, 2017.

PAES, E.T.; ALCANTARA, A.V.; GUIMARÃES, C.R.P.; ARAUJO, H.M.P.; ALVES, J.P.H. Caracterização ecológica e oceanográfica da plataforma continental do Estado de Sergipe: um ambiente costeiro equatorial sob a influência de águas subantárticas. In: CONGRESSO LATINO-AMERICANO DE CIÊNCIAS DO MAR, XII, Florianópolis. 2007. Resumo expandido... Florianópolis, 2007.

PILKEY, O.H.; MORTON, R. W.; LUTERNAUER, J. The carbonate fraction of beach and dune sands. Sedimentology. v. 8, p. 311-327, 1967.

POGGIO, C.A.; SOUZA, F.B.C.; ALVES, O.F.S; DOMINGUEZ, J.M.L. Distribuição dos componentes biogênicos nos sedimentos da área do canal de Salvador, Baía de Todos os Santos, Bahia. Quaternary and Environmental Geosciences, v. 01, n. 01, p. 10-15, 2009.

POPP, J. H. Geologia Geral. 5. Ed. Rio de Janeiro: Livros Técnicos e Científicos, 2002.

QUEIROZ, E.V.; ARAÚJO, P.V.N.; HAMMILL, E.; AMARAL, R.F. Morphological characteristics of rhodolith and correlations with associated sediment in a sandstone reef: Northeast Brazil. Regional Studies in Marine Science. n. 8, p. 133-140, 2016. http://dx.doi.org/10.1016/j.rsma.2016.10.005.

REBOUÇAS, R.C. Sedimentação Holocênica da plataforma continental de Salvador - BA. Salvador-Bahia, 2010, 90 p. Tese (Doutorado). Instituto de Geociências, Universidade Federal da Bahia.

REBOUÇAS, R.C.; DOMINGUEZ, J.M.L.; BITTENCOURT, A.C.S.P. Provenance, transport and composition of dendê coast beach sands in Bahia, central coast of Brazil. Brazilian Journal of Oceanography, v. 59, n. 4, p. 339-347, 2011. DOI: https://doi.org/10.1590/S1679-87592011000400004.

SANTOS, J.R. Caracterização Morfodinâmica e Sedimentologia da Plataforma Continental Rasa na APA Estadual dos Recifes de Corais - RN. Natal. 2010. 85 p., Dissertação (Mestrado em Geodinâmica e Geofísica). Centro de Ciências exatas e da Terra - Universidade Federal do Rio Grande do Norte.

SCHREINER, S.; FERREIRA, E. T. I.; OLIVEIRA JR., E. A. Modelo digital da geomorfologia do fundo oceânico do centro-sul da Bacia de Sergipe-Alagoas. Boletim de 
Geociências da Petrobras, Rio de Janeiro, v. 23, n. 1, 6p. 2015.

SHANNON, C.E. \& WEAVER, W. The Mathematical Theory of Communication. Then University of Illinois Press, Urbana. 1964.

SHEPARD, F.P. Nomenclature Based on Sand-Sil-Clay Ratios. Journal of Sedimentary. Petrology, v. 24, n. 3, p. 151 - 158, 1954.

Silveira, I.C.; Miranda, L.B. Brown, W.S. On the origins of the North Brazil Current. Journal of Geophysical Research: Oceans (1978-2012), v. 99 (C11), p. 22501-22512, 1994.

SIMÕES, M. G. \& HOLZ, M. Tafonomia: Processos e ambientes de fossilização. In: CARVALHO, I. S. Paleontologia. 2 ed. v. 1. Rio de Janeiro: Interciências, 2004.

TEJEDA-CRUZ, C.; MEHLTRETER, K.; SOSA, V. J., Indicadores ecológicos multi-taxonómicos. In: Roberto $\mathrm{H}$. Manson, Vicente Hernández Ortiz, Sonia Gallina y Klaus Mehltreter (Editores). 2008. Agroecosistemas Cafetaleros de Veracruz. Biodiversidad Manejo y Conservación. Instituto de Ecología e Instituto Nacional de Ecología. 330 p.

VASCO, A.N.; AGUIAR NETTO, A.O.; PRUSKI, F.F. Impactos das barragens na disponibilidade hídrica do Nordeste do Brasil. Recursos Hídricos (Lisboa), v. 38, p. 39-49, 2017. VIEIRA, L.R.S. \& MANSO, C.L.C. Textural and compositional variations in beach sands along south Alagoas coast, Brazil. Revista de Gestão Costeira Integrada, v. 17, n. 2, p. 139149, 2017. DOI: 10.5894/rgci-n99.

VITAL, H.; SILVEIRA, I. M.; AMARO, V. E. Carta Sedimentológica da Plataforma Continental Brasileira - Área Macau (NE Brasil), Utilizando Integração de Dados Geológico e Sensoriamento Remoto. Revista Brasileira de Geofísica, v. 23, n. 3, p. 233-241, 2005.

WESTPHAL, H.; HALFAR, J; FREIWALD, A. Heterozoan carbonates in subtropical to tropical settings in the present and past. Int J Earth Sci (Geol Rundsch), v. 99 (Suppl 1), p. S153-S169, 2010. DOI 10.1007/s00531-010-0563-9.

Submetido em 17 de outubro de 2018 Aceito em 12 de fevereiro de 2019 